\title{
The impact of human resource management practices and job satisfaction on employee performance in the ministry of foreign affairs of Kuwait
}

\author{
D.O.I - 10.51201/Jusst12683
}

http://doi.org/10.51201/Jusst12683

\author{
Bader Ali Almutairi ${ }^{1}$ \\ ${ }^{1}$ Faculty of Business \& Finance, The World Islamic Sciences \& Education University, Jordan \\ Khuzama Mohammad Arabiat ${ }^{2}$ \\ ${ }^{2}$ Faculty of Business \& Finance, The World Islamic Sciences \& Education University, Jordan
}

\begin{abstract}
The current study aims to examine the human resource management practices and job satisfaction on employee performance and examine the mediating role of job satisfaction in the ministry of foreign affairs of Kuwait. The survey included 212 employees are working in the ministry of foreign affairs of Kuwait. The results of this study indicated that human resource management practices have a positive direct effect on employee performance. Moreover, the results of this study indicated that human resource management practices have a positive direct effect on job satisfaction. The results of this study indicated also that job satisfaction has a positive direct effect on employee performance. Regarding the mediating role, the results indicated that job satisfaction mediated the impact between human resource management practices and employee performance. Organizations should implement human resource management practices to strengthen and boost their future performance. As organizations should increase the level of job satisfaction in order to improve the performance of employees. This study recommended replicated the context of this study in other sectors in Kuwait such as the health care sector, education sector, and private sector.
\end{abstract}

Keywords: Human Resource Management Practices, Employee Performance, Job Satisfaction

\section{Introduction}

At the level of the government sector, employee performance is a very important factor in public service because it reflects the image of the government and the efficiency of the government sector. High job performance increases citizen confidence in government image and service (Alessandri, Borgogni \& Latham, 2017).Employee performance consists of the observable behaviors that employees do in their careers that are relevant to the objectives of the companies (Fogaça et al., 2018). Employee performance is of interest to organizations because of the importance of high productivity in the workplace (Alessandri, Borgogni \& Latham, 2017).

Performance definitions should focus on behaviors rather than results (Saad \& Abbas, 2018) because a focus on results could lead employees to find the easiest way to achieve the desired results, which is likely to be detrimental to the companies because other important behaviors will not be performed. From the perspective of Peiró, Bayona, Caballer, and Fabio (2020) performance are not the outcomes of behaviors, but rather the behaviors themselves. Therefore, performance consists of the behaviors that employees actually engage in which can be observed. Therefore, this study aims to examine the human resource management practices and job satisfaction on employee performance, and examine the mediating role of job satisfaction in the ministry of foreign affairs of Kuwait. 


\section{Literature Review}

\subsection{Human Resource Management Practices}

Human resource management practices are defined as "a set of distinct but interrelated activities, functions, and processes that are directed at attracting, developing, and maintaining a firm's human resource" (Lado \& Wilson, 1994, p. 701). Moreover, human resource management practices are a collection of methods, strategies, and philosophies that aim to intend to attract, develop, inspire and retain the employees, in order to ensure the effectiveness of employees and the work continuity of the organizations to achieve the strategic objectives to these organizations (Aburumman, Salleh, Omar \& Abadi, 2020).

Study of Vivares, Sarache, and Naranjo (2016) aimed to investigate the impact of human resource management on the performance of the competitive priorities of medium and large manufacturing companies in Colombia. This study used the questionnaire as a tool to collect data, and the study population consisted of (48) medium and large manufacturing companies in Colombia. The questionnaire was sent to each of the production directors and the director of the human resources department for each company, from whom he received (36) and (39) questionnaires respectively. The data were analyzed by using PLS-SEM in order to test hypotheses and obtain results. The results indicate that there is no significant relationship between human resource management practices and the performance of competitive priorities. As for the employee-related factors, there were two important outcomes: First, when companies incorporate features about individuals in the decision-making process of the operating system (motivations, personal goals, and abilities) better performance of competitive priorities can be observed. Second, when employees reach a higher level of job satisfaction and job performance, the performance of competitive priorities improves.

Study of Adil (2015) aimed to investigate the impact of strategic HRM practices (recruitment, selection, performance evaluation, training and development, compensation, rewards, job security, job description, job opportunities, decentralization, and empowerment) on the competitive priorities (cost, quality, connectivity, and flexibility) in Pakistani industrial companies. This study used the questionnaire as a tool to collect data. A total of (218) questionnaires were distributed to 90 industrial companies (including 15 industrial sectors) based in Karachi, Pakistan. (182) valid questionnaires were received for the analysis. The data were analyzed through the use of the statistical program (SPSS and AMOS) in order to test the hypotheses and obtain the results. The results of the study show that all strategic human resource management practices collectively show a significant impact on competitive priorities, however, it was found that job performance and security assessment are of statistical significance for predicting competitive priorities (cost, quality, connectivity, and flexibility) more than other practices. The study recommends future research to study how to manage these four competitive priorities (cost, quality, delivery, and flexibility) to gain and maintain a competitive advantage.

Study of Atikbay and Öner (2016) aimed to investigate the relationship between human resource management practices and organizational cynicism through the mediating role of organizational justice in managing municipalities in a developing country in Northern Cyprus. This study used a questionnaire as a data collection tool. This study targeted employees in the municipal administration in North Cyprus. This study relied on a nonprobability sampling technique through the convenience sampling method for easy access to the participants. 366 valid questionnaires were obtained for the analysis. The data were analyzed by using the statistical program (AMOS and SPSS) in order to test the hypotheses and obtain the results. The results indicate that organizational justice mediates the 
relationship between human resource management practices and organizational cynicism, as the results demonstrate that effective application of contemporary human resource management practices approach enhances the perception of organizational justice and at the same time helps to reduce organizational cynicism.

\subsection{Employee Performance}

Employee performance is one of the important variables that is studied widely (Staw, 1984). Employee performance is a multidimensional construct (Zamanan et al., 2020) and is a central construct in organizational psychology (Murphy \& Cleveland, 1995). Campbell, Mchery, and Wise (1990) define Employee performance as individual behaviors which meet organization goals. Employee performance also refers to the activities of the individuals at the workplace, that directly or indirectly contribute to achieving the organization's goals (Viswesvaran \& Ones, 2000). Additionally, Jex and Britt (2008) define employee performance, as the behaviors that are properly assessed by the organization as a part of employees' responsibilities and duties.

Study of Ababneh, Hayajneh, and Al-Waked (2014) aimed to know the level of organizational justice and its impact on the performance of the employees of the Cities and Villages Development Bank of Jordan from the point of view of its employees, who numbered 383 from several administrative levels. A random sample of 170 individuals was chosen to distribute questionnaires to them, to retrieve 162 questionnaires, of which 153 were valid for analysis. The results of the study showed that organizational justice in CVDB came at a low level. Where (interactive justice) came first at an intermediate level, while (distributive justice) and (procedural justice) came second and third, respectively, at a low level. The results of the study also showed that the performance of CVDB employees came at an average level, as (size, quality, speed, and accuracy) of their performance came at a medium level, and the results of the study also showed a statistically significant effect of organizational justice in its three dimensions (distributional, procedural, and interactive) The performance of the employees as a whole in the Jordan Cities and Villages Development Bank in all its branches and offices in the Kingdom, and the existence of statistically significant differences between the arithmetic averages of the estimates of the study sample individuals on the tool as a whole and each of its related fields except for distributive justice attributable to a change job title, and in favor of the estimates of workers with Job title (employee).

Study of Kalay and Turkey (2016) aimed to analyze the effects of three aspects of organizational justice, namely, distributive justice, procedural justice, and interactive justice, on the performance of employees' tasks in the context of Turkey. The study was conducted on the basis of data collected from 942 teachers working in public schools in three Turkish metropolitan cities. The hypotheses were tested using partial structural equation modeling (PLS-SEM) techniques. The results of the study indicated that fairness in distribution among the three aspects of organizational justice has a positive and significant impact on task performance. However, other aspects, procedural justice, and reactive justice have been shown to have no significant impact on task performance.

Study of Diab (2015) aimed to find out whether there is an effect of organizational justice on employees' performance and job satisfaction in Ministry of Health hospitals in Amman. Data for this study were collected through a questionnaire of 300 workers in different jobs in three hospitals in the Ministry of Health in Amman. The results of the study found that there is a positive relationship for the organizational justice dimensions (distributive justice, procedural 
justice, reactive justice, developmental justice) on employees performance, and employees satisfaction in the hospitals of the Ministry of Health in Amman (Ministry of Health), separately and socially, there is also a difference in feelings of dimensions of organizational justice among workers in the (Ministry of Health) according to demographic variables (gender, age, marital status, experience, qualifications, and position). The study also found that there is a very high perception with dimensions of organizational justice among employees in (Ministry of Health). Distributive justice was the highest perception; the lowest perception was reactive justice.

\subsection{Job Satisfaction}

Job satisfaction is a pleasurable emotional state resulting from the appraisal of one's job as achieving or facilitating the achievement of one's job values (Locke, 1969). Many organizations focus more attention on measuring the career satisfaction level of staff in trying to predict primary behaviors of employees, namely job performance, leaving a job, or stopping work (Salleh et al., 2020; Swider, Boswell \& Zimmerman, 2011). Surveys conducted also show that treating employees with respect, providing regular employee recognition, empowering employees, offering above industry-average benefits, compensation, job security, the opportunity for advancement, comfortable working conditions, good personal relations with colleagues and supervisors, achievement and promotion are some of the factors that lead to employee satisfaction (Aburumman, Salleh, Omar \& Abadi, 2020; Nazir, 1998; Fu \& Deshpande, 2012; Zamanan et al., 2020).

Study of Al-Douri (2020) aimed to examine the relationship between organizational justice (distributive justice, procedural justice, and interactive justice) and job satisfaction of employees in the logistics sector in the transport industry in Jordan. This study used the questionnaire as a tool to collect data. The questionnaire was distributed to a sample of the population studied in this survey. The data were analyzed by using the statistical program (SPSS) in order to test the hypotheses and obtain the results. The results indicate that organizational justice has a significant impact on job satisfaction of employees, and procedural justice also had an effect on job satisfaction, which means the importance of showing a clear interest in work-related procedures, and the effect of reactive justice on job satisfaction was found to be relatively high. While distributive justice has no effect on job satisfaction, which means that there is no effect of delegating and sharing powers with employees, nor does the distribution of equal opportunities and work schedules affect job satisfaction. The study recommends that managers encourage working through a single team and build good relationships with all employees, help employees to evaluate themselves and strive to solve disputes and conflicts fairly.

Study of Azbari, Akbari, and Chaijani (2015) aimed to identify the impact of strategic leadership and empowerment on employee satisfaction at Gilan University in Iran. The study sample included (235) employees. An effect of strategic leadership on employee satisfaction was found, and an impact of empowerment on employee satisfaction was found, and an impact of both strategic leadership and empowerment on employee satisfaction was found.

Hypothesis 1:Human resource management practices have a significant impact on employee performance in the ministry of foreign affairs of Kuwait.

Hypothesis 2:Human resource management practices have a significant impact on job satisfaction in the ministry of foreign affairs of Kuwait.

Hypothesis 3:Job satisfaction has a significant impact on employee performance in the ministry of foreign affairs of Kuwait. 
Hypothesis 4:Job satisfaction mediate the relationshipbetweenhuman resource management practices and employee performance in the ministry of foreign affairs of Kuwait.

Therefore, this study aims to examinethe human resource management practices and job satisfaction on employee performance, and examinethe mediating role of job satisfaction in the ministry of foreign affairs of Kuwait. The study model is shown in Figure 1.

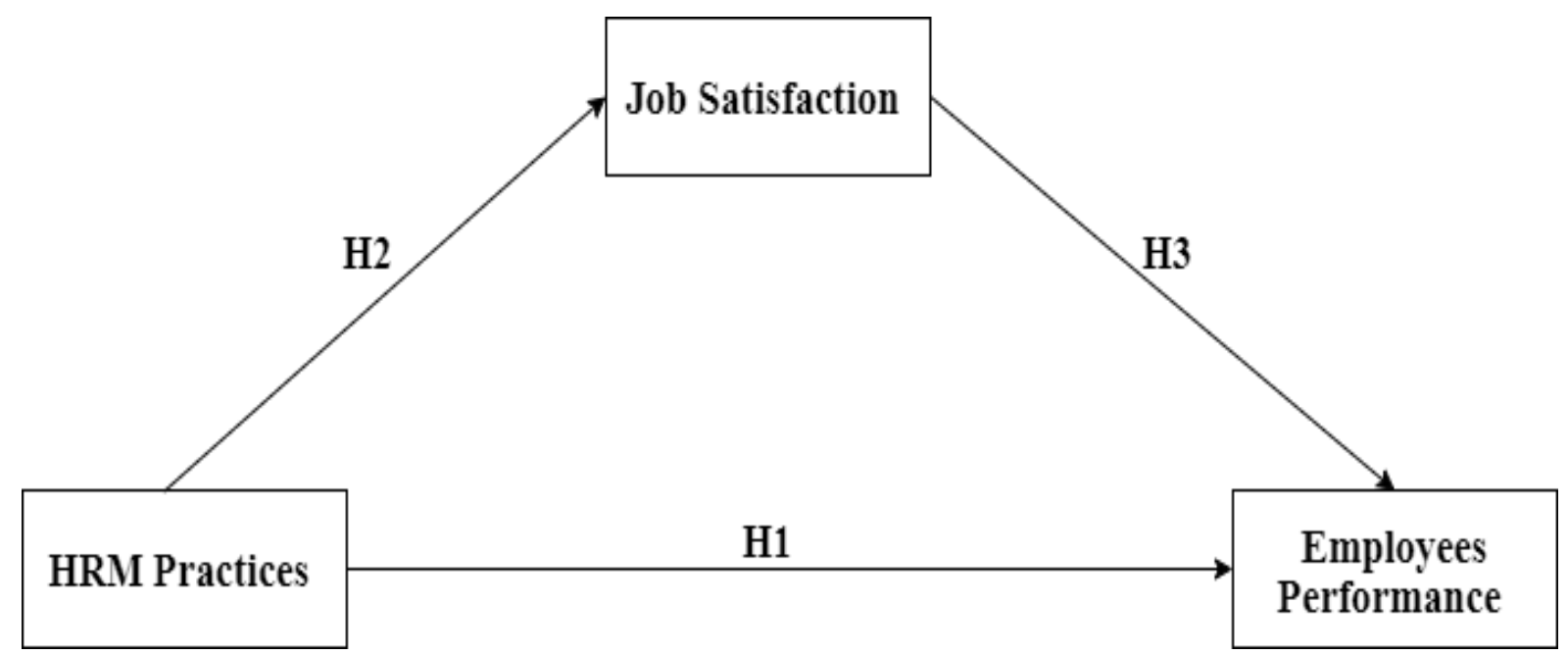

\section{Methodology}

Figure 1: Study model

This study used a quantitative approach based on a survey questionnaire. The survey included employees in the ministry of foreign affairs of Kuwait. The close-structured questionnaire was adopted from previous studies. The study sample size was 212 employees are working in the ministry of foreign affairs of Kuwait. In order for data collection, convenience sampling has been used as a technique for data collection, where that convenience sampling usually requires less time and inexpensive (Salleh, Omar, Aburumman, Mat \& Almhairat, 2020). The total number of responses was 196, which represents $92.4 \%$ of the number of distributed questionnaires, and a total of 16 questionnaires were not received.

\section{Data Analysis}

\subsection{Assessment of Measurement Model}

The current study used SmartPLS (3.3.3) to assessment of measurement model, which included convergent validity and discriminant validity. Table 1 shows the results of convergent validity, where all the items have loadings ranged from 0.735 to 0.934 . Regarding Cronbach's alpha and composite reliability, all variables achieved values more than 0.7 . Meanwhile, all variables achieved values more than 0.5 regarding average variance extracted. Thus, all variables achieved values greater than the proposed threshold value by Hair et al. (2016). 
Table 1: Convergent Validity

\begin{tabular}{|c|c|c|c|c|c|}
\hline Variable & Items & Loadings & $\begin{array}{c}\text { Cronbach's } \\
\text { Alpha }\end{array}$ & $\begin{array}{l}\text { Composite } \\
\text { Reliability }\end{array}$ & AVE \\
\hline \multirow[t]{16}{*}{ HRM Practices } & HRMP1 & 0.819 & $\mathbf{0 . 9 7 3}$ & 0.975 & 0.712 \\
\hline & HRMP2 & 0.804 & & & \\
\hline & HRMP3 & 0.807 & & & \\
\hline & HRMP4 & 0.874 & & & \\
\hline & HRMP5 & 0.856 & & & \\
\hline & HRMP6 & 0.910 & & & \\
\hline & HRMP7 & 0.846 & & & \\
\hline & HRMP8 & 0.805 & & & \\
\hline & HRMP9 & 0.759 & & & \\
\hline & HRMP10 & 0.901 & & & \\
\hline & HRMP11 & 0.735 & & & \\
\hline & HRMP12 & 0.884 & & & \\
\hline & HRMP13 & 0.865 & & & \\
\hline & HRMP14 & 0.881 & & & \\
\hline & HRMP15 & 0.829 & & & \\
\hline & HRMP16 & 0.898 & & & \\
\hline \multirow[t]{5}{*}{ Job Satisfaction } & JS1 & 0.843 & 0.935 & 0.951 & 0.795 \\
\hline & JS2 & 0.879 & & & \\
\hline & JS3 & 0.934 & & & \\
\hline & JS4 & 0.867 & & & \\
\hline & JS5 & 0.931 & & & \\
\hline \multirow[t]{6}{*}{ Employee Performance } & EP1 & 0.931 & 0.943 & 0.955 & 0.779 \\
\hline & EP2 & 0.896 & & & \\
\hline & EP3 & 0.867 & & & \\
\hline & EP4 & 0.851 & & & \\
\hline & EP5 & 0.837 & & & \\
\hline & EP6 & 0.909 & & & \\
\hline
\end{tabular}

Discriminant validity was investigated based on Heterotrait-Monotrait Ratio (HTMT). Table 2 shows HTMT values were all smaller than 1 for each construct and were within the range of 0.930 to 0.986 (Hair et al., 2016).

Table 2: Discriminant Validity Based on HTMT

\begin{tabular}{lccc}
\hline & HRM Practices & $\begin{array}{c}\text { Job } \\
\text { Satisfaction }\end{array}$ & $\begin{array}{c}\text { Employee } \\
\text { Performance }\end{array}$ \\
\hline HRM Practices & & & \\
\hline Job Satisfaction & 0.931 & & \\
\hline Employee Performance & 0.930 & 0.986 & \\
\hline
\end{tabular}

\subsection{Assessment of Structural Model}

In order to assessment of structural model, the path coefficients were created using the PLS algorithm embedded with SmartPLS (3.3.3) as shown in Figure 2. 


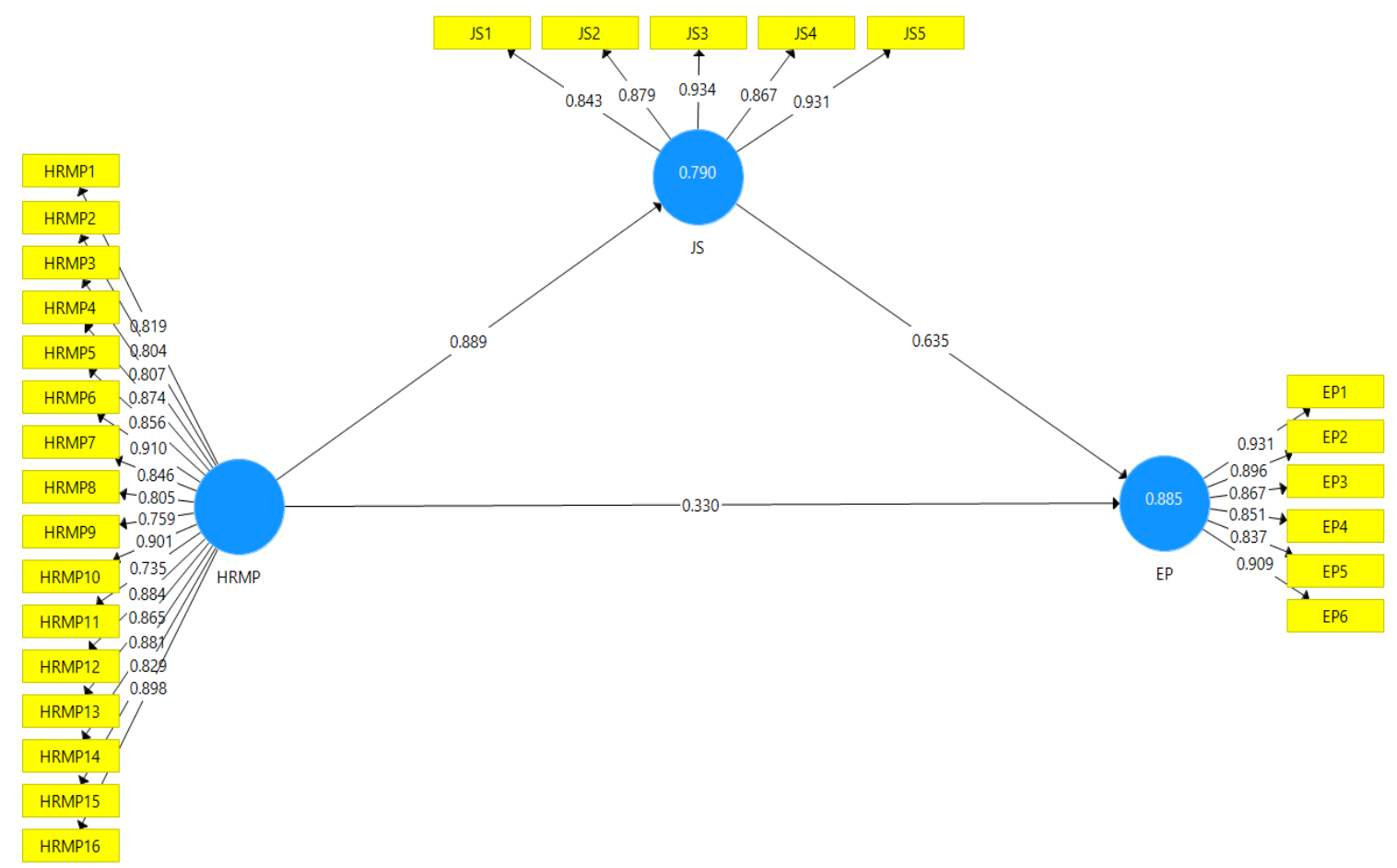

Figure 2:Path Coefficients

After created the path coefficients, the next step was test the P-Values and T-Values for each path coefficient in order to conclude whether the hypotheses are statistically significant or insignificant using bootstrapping techniques embedded with SmartPLS (3.3.3). Table 3 shown the hypotheses test.

Table 3: Hypotheses testing

\begin{tabular}{|c|c|c|c|c|c|c|c|}
\hline \multirow[b]{2}{*}{ No. } & \multirow[b]{2}{*}{ Hypotheses } & \multirow{2}{*}{$\begin{array}{c}\text { Path } \\
\text { Coefficient }\end{array}$} & \multirow[b]{2}{*}{ T-Value } & \multirow[b]{2}{*}{ P-value } & \multicolumn{2}{|c|}{ Confidence Interval } & \multirow[b]{2}{*}{ Decision } \\
\hline & & & & & $95 \% \mathrm{LL}$ & 95\% UL & \\
\hline H1 & $\mathrm{HRMP} \rightarrow \mathrm{EP}$ & 0.330 & 2.405 & 0.016 & 0.089 & 0.623 & Supported** \\
\hline H2 & $\mathrm{HRMP} \rightarrow \mathrm{JS}$ & 0.889 & 44.234 & 0.000 & 0.840 & 0.921 & Supported*** \\
\hline H3 & $\mathrm{JS} \rightarrow \mathrm{EP}$ & 0.635 & 5.004 & 0.000 & 0.361 & 0.854 & Supported*** \\
\hline
\end{tabular}

As shown in Table 3, human resource management practices have a positive direct effect on employee performance (Path Coefficient $=0.330 ; \mathrm{T}$-Value $=2.405 ; \mathrm{P}-$ Value $=0.016 ; 95 \%$ $\mathrm{LL}=0.089 ; 95 \% \mathrm{UL}=0.623)$, therefore $\mathrm{H} 1$ was supported. In contrast, human resource management practices have a positive direct effect on job satisfaction (Path Coefficient $=$ $0.889 ; \mathrm{T}-$ Value $=44.234 ; \mathrm{P}-$ Value $=0.000 ; 95 \% \mathrm{LL}=0.840 ; 95 \% \mathrm{UL}=0.921)$, therefore $\mathrm{H} 2$ was supported. Moreover, job satisfaction has a positive direct effect on employee performance $($ Path Coefficient $=0.635 ; \mathrm{T}-$ Value $=5.004 ; \mathrm{P}-$ Value $=0.000 ; 95 \% \mathrm{LL}=0.361$; $95 \% \mathrm{UL}=0.854)$, thereforeH3 was supported. Regarding the mediating effect of job satisfaction, as shown in Table 4, job satisfaction mediated the effect between shuman resource management practicesandemployee performance (Indirect Effect $=0.565$; T-Value $=$ 5.192; P-Value $=0.000 ; 95 \% \mathrm{LL}=0.330 ; 95 \% \mathrm{UL}=0.752$ ), thereforeH4 was supported. 
Table 4: Testing the mediating effect of job satisfaction

\begin{tabular}{lccccccc}
\hline No. & Hypothesis & $\begin{array}{c}\text { Indirect } \\
\text { Effect }\end{array}$ & T-Value & P-value & \multicolumn{2}{c}{ Confidence Interval } & \multirow{2}{*}{ Decision } \\
\hline H4 & HRMP $\rightarrow$ & 0.565 & 5.192 & 0.000 & 0.330 & 0.752 & \multirow{2}{*}{ Supported $* * *$} \\
\hline NSte: $* * *: \mathrm{p}<0.001$ & & & & & & \\
\hline Non & & & & & & &
\end{tabular}

\section{Conclusion}

This study aims to examine human resource management practices and job satisfaction on employee performance, and examine the mediating role of job satisfaction in the ministry of foreign affairs of Kuwait. The results of this study indicated that human resource management practices have a positive direct effect on employeeperformance. This result was consistent with those reported by many studies (e.g.Atikbay \& Öner 2016; Adil, 2015; Vivares, Sarache, \& Naranjo, 2016). Moreover, the results of this study indicated that human resource management practices have a positive direct effect on job satisfaction. This result was consistent with those reported by many studies (e.g. Azbari, Akbari \& Chaijani. 2015; Aburumman, Salleh, Omar \& Abadi, 2020; Fu \& Deshpande, 2012; Zamanan et al., 2020). The results of this study indicated also that job satisfaction has a positive direct effect on employeeperformance. This result was consistent with those reported by many studies (e.g. Bayona, Caballer \& Peiró, 2020; Gul, Usman, Liu, Rehman \& Jebran, 2018; Karem, Mahmood, Jameel \& Ahmad, 2019; Shaju \& Subhashini, 2017). Regarding the mediating variable, the results indicated that job satisfaction mediated the effect between human resource management practices and employee performance.Human resource management practices can play a significant and essential role in employee performance in any organization. Therefore, in order to improve employee performance, organizations should implement HRM practices to strengthen and boost their future performance. Moreover, job satisfaction plays a vital role to increase employee performance according to our results. Therefore, organizations could improve the performance of the employees by job satisfaction through giving them good salaries, improving the promotion process, improving working conditions.Regarding future studies, this study recommended replicated the context of this study in other sectors in Kuwait such as the health care sector, education sector, and private sector.

\section{References}

Ababneh, A., Hayajneh, C., Al-Waked, L. (2014). The level of organizational justice and its impact on the performance of the employees of the Cities and Villages Development Bank of Jordan from the viewpoint of its employees. The Islamic University Journal of Economic and Administrative Studies, 22 (2), 197-229.

Aburumman, O., Salleh, A., Omar, K., \& Abadi, M. (2020). The impact of human resource management practices and career satisfaction on employee's turnover intention. Management Science Letters, 10(3), 641-652.

Adil, M. S. (2015). Strategic human resource management practices and competitive priorities of the manufacturing performance in Karachi. Global Journal of Flexible Systems Management, 16(1), 37-61.

Al-Douri, Z. (2020). Organizational justice and its impact on job satisfaction: Evidence from transportation industry. Management Science Letters, 10(2), 351-360.

Alessandri, G., Borgogni, L., \& Latham, G. P. (2017). A dynamic model of the longitudinal relationship between job satisfaction and supervisor-rated job performance. Applied Psychology, 66(2), 207-232. 
Atikbay, T., \& Öner, Y. (2020). Effects of human resources management practices and organizational justice perceptions on organizational cynicism: A research on municipalities in a developing country. Management Science Letters, 10(8), 1659-1670.

Azbari, M., Akbari, M. Chaijani, M.(2015), The effect of strategic leadership and empowerment on job satisfaction of the employees of University of Guilan , International Journal of Organizational Leadership, 4, 453-464

Bayona, J. A., Caballer, A., \& Peiró, J. M. (2020). The relationship between knowledge characteristics' fit and job satisfaction and job performance: The mediating role of work engagement. Sustainability, 12(6), 2336.

Campbell, J. P., McHenry, J. J., \& Wise, L. L. (1990). Modeling job performance in a population of jobs. Personnel Psychology, 43(2), 313-575.

Diab, S. (2015). The Impact of Organizational Justice on the Workers Performance and Job Satisfaction in the Ministry of Health Hospitals in Amman. International Business Research, 8(2), 187-197.

Fogaça, N., Rego, M. C. B., Melo, M. C. C., Armond, L. P., \& Coelho Jr, F. A. (2018). Job performance analysis: scientific studies in the main journals of management and psychology from 2006 to 2015. Performance Improvement Quarterly, 30(4), 231-247.

$F u, W .$, \& Deshpande, S. P. (2014). The impact of caring climate, job satisfaction, and organizational commitment on job performance of employees in a China's insurance company. Journal of business ethics, 124(2), 339-349.

Gul, H., Usman, M., Liu, Y., Rehman, Z., \& Jebran, K. (2018). Does the effect of power distance moderate the relation between person environment fit and job satisfaction leading to job performance? Evidence from Afghanistan and Pakistan. Future Business Journal, 4(1), 68-83.

Jex, S. \& Britt, T. W. (2008). Organizational psychology: A scientist-practitioner approach (2nd ed.). Hoboken, NJ: Wiley

Kalay, F. \&Turkey,V. (2016). The Impact of Organizational Justice on Employee Performance: A Survey in Turkey and Turkish Context. International Journal of Human Resource Studies, 6(1),1-21.

Karem, M. A., Mahmood, Y. N., Jameel, A. S., \& Ahmad, A. R. (2019). The effect of job satisfaction and organizational commitment on nurses' performance. Journal of Humanities and Social Sciences Reviews. eISSN, 2395-6518.

Lado, A. A., \& Wilson, M. C. (1994). Human resource systems and sustained competitive advantage: A competency-based perspective. Academy of Management Review, 19(4), 699-727.

Locke, E. A. (1969). What is job satisfaction?. Organizational behavior and human performance, 4(4), 309-336.

Murphy, K.R. \& Cleveland, J.N. (1995). Understanding Performance Appraisal: Social, Organizational, and Goal-based Perspectives. Thousand Oaks, CA: Sage.

Nazir, N. A. (1998). Perceived importance of job facets and overall job satisfaction of bank employees. Indian Journal of Industrial Relations, 479-496.

Peiró, J. M., Bayona, J. A., Caballer, A., \& Di Fabio, A. (2020). Importance of work characteristics affects job performance: The mediating role of individual dispositions on the work design-performance relationships. Personality and Individual Differences, 157, 109808.

Saad, G. B., \& Abbas, M. (2018). The impact of organizational culture on job performance: a study of Saudi Arabian public sector work culture. Problems and Perspectives in Management, 16(3), 207-218. 
Salleh, A. M. M., Omar, K., Aburumman, O. J., Mat, N. H. N., \& Almhairat, M. A. (2020). The impact of career planning and career satisfaction on employee's turnover intention. Entrepreneurship and Sustainability Issues, 8(1), 218.

Shaju, M., \& Subhashini, D. (2017). A Study on the Impact of Job Satisfaction on Job Performance of Employees Working in Automobile Industry. Journal of Management Research (09725814), 17(2).

Staw, B. M. (1984). Organizational behavior: A review and reformulation of the field's outcome variables. Annual review of psychology, 35(1), 627-666.

Swider, B. W., Boswell, W. R., \& Zimmerman, R. D. (2011). Examining the job searchturnover relationship: The role of embeddedness, job satisfaction, and available alternatives. Journal of applied psychology, 96(2), 432.

Viswesvaran, C., \& Ones, D. S. (2000). Perspectives on models of job performance. International Journal of Selection and Assessment, 8(4), 216-226.

Vivares-Vergara, J. A., Sarache-Castro, W. A., \& Naranjo-Valencia, J. C. (2016). Impact of human resource management on performance in competitive priorities. International Journal of Operations \& Production Management, 36(2), 114-134.

Zamanan, M., Alkhaldi, M., Almajroub, A., Alajmi, A., Alshammari, J., \& Aburumman, O. (2020). The influence of HRM practices and employees' satisfaction on intention to leave. Management Science Letters, 10(8), 1887-1894. 